\title{
Determination of Nutritional Status of Under-Five Year Children Employing Multiple Interrelated Contributing Factors in Southern Part of Bangladesh
}

\author{
Rajib Kanti Roy, Md Shahajahan Matubbar, Md Kamruzzaman, Asad Ud-Daula* \\ Department of Applied Nutrition and Food Technology, Faculty of Applied Science and Technology, Islamic University, Kushtia-7003, \\ Bangladesh
}

\begin{abstract}
Email address:
rajib131kushtia@gmail.com (R. K. Roy), smatubbar@yahoo.com (Md S. Matubbar),mkzaman.m@gmail.com (Md Kamruzzaman), asad.uddaula@googlemail.com (A. Ud-Daula)
\end{abstract}

\section{To cite this article:}

Rajib Kanti Roy, Md Shahajahan Matubbar, Md Kamruzzaman, Asad Ud-Daula. Determination of Nutritional Status of Under-Five Year Children Employing Multiple Interrelated Contributing Factors in Southern Part of Bangladesh. International Journal of Nutrition and Food Sciences. Vol. 4, No. 3, 2015, pp. 264-272. doi: 10.11648/j.ijnfs.20150403.13

\begin{abstract}
Objectives: Children under-five years are more vulnerable and susceptible to malnutrition especially in the coastal region. Therefore, this study sought to find out the contributing factors of malnutrition among under-five children in coastal region of Bangladesh.Study Design: It is descriptive type cross-sectional study.Methods: Anthropometric methods and structured questionnaires were used to collect required data. Nutritional status was measured using $\mathrm{Z}$ score according to WHO classification. 175 children (6-59 months) and their householdin Barguna district was considered for study subjects. Results and discussion:Only $5.7 \%$ children were introduced with colostrum and $25.71 \%$ followed exclusive breast feeding. The rate of literacy was found to be higher in father $(85.1 \%)$ as compared to mother $(39.4 \%) .68 .6 \%$ children are suffering from underweight whereas the percentage of wasting and stunting children were found to $40.6 \%$ and $60 \%$ respectively. Breastfeeding practice and monthly family income were significantly associated with wasting, stunting and underweight. Children who were not exclusively breast fed had higher rate of moderate wasting (59.5\%), stunting (70.5\%) and underweight $(74.6 \%)$. Children with illiterate father were found to have more odd value of having wasting, stunting and underweight compared to literate father. Furthermore, early age (6-24 month) of children are more susceptible for malnutrition as compared to the age (25-59 months) of children. Conclusions: Children are underweight and stunting due to the insufficient breast feeding practice, father's education, monthly income of families and sanitary practices. Therefore, community nutrition and public health education are early demands for the people in the coastal area.
\end{abstract}

Keywords: Anthropometric Assessment, Breastfeeding, Socioeconomic-Demographic, Wasting, Stunting

\section{Introduction}

Malnutrition is referred to the under-nutrition and overnutrition. In Bangladesh under-nutrition is more prevalent. It includes children being underweight for one's age, too short for one's age (stunted), dangerously thin for one's height (wasted) and deficient in vitamins and minerals (micronutrient malnutrition)[1].Malnutrition among underfive yearschildren is a chronic problem in developing countries. In 2010, it has been reported that, $27 \%$ of children under fiveyears (171 million) are stunted and 16\% (104 million) are underweight globally[2].It is also alarming that 10.5 million children of age under-five years die worldwide every yearand $98 \%$ of these deaths reported to occur in developing countries [1].Therefore, child malnutrition is the most widely spread health disorder throughout the world [3].Malnutrition contributes to more than one-third of all deaths of under-five year children [4]. Currently, 195 million under-five children are affected by malnutrition; $90 \%$ of them live in sub-Saharan Africa and South Asia [5].

The nutritional status of the people of Bangladesh is considered to be worse among Asian countries, and Bangladesh ranks $57^{\text {th }}$ in relation to children aged less than 5 years, and the prevalence of childhood malnutrition in Bangladesh is one of the highest in the world; about $43 \%$ of under-5 year children are stunted, $41 \%$ have underweight and about $17 \%$ suffer from wasting [6].Therefore, the present nutritional status of the population in Bangladesh can easily 
be compared with a "Silent Emergency". Although, the prevalence of malnutrition among children of under five year of age is decreasing, it is still very high-about 40 percent of children of under-five years are stunted and 12 percent are wasted, according to the 2004 Bangladesh Demographic and Health Survey [7]. It is also reported that stunting, wasting and underweight are associated with place of residence (rural or urban), maternal education, age and nutritional status [8]. It was estimated that about 2 million (14\%) of children under fiveyears in Bangladesharesuffering from acute undernutrition (wasting) [9]. Previous studies have shown that multiple family and household characteristics were associated with malnutrition into under-five yearschildren [10].However, the cause of an individual's nutritional status is influenced by three broad categories of factors - food, care and health. Underlying and more basic causes include poverty, illiteracy, social norms and behaviour. Maternal nutrition and health greatly influences child nutritional status. Household food security, often influenced by such factors as poverty, drought and other emergencies, has an important role in determining the state of child and maternal nutrition in many countries.

Overpopulation and poverty are pervasive in Bangladesh that causing population hazards like malnutrition. Specially, under five years children who are naturally dependent, vulnerable and susceptible to infections often suffering from malnutrition. This situation is worst in the southern coastal part of Bangladesh, where persistent salinity and frequent occurrence of natural disasters pushed the entire population at risk of food insecurity, which in turn deteriorates other conditions that affect the nutritional status. Therefore, children living in the southern regions have extreme possibility of being severely malnourished.Although, Bangladesh Integrated Nutrition Project (BINP) and National Nutrition Project (NNP) claims to have achieved a better nutritional status of children in the entire country, but scarcely conducted any specific research to know the current nutritional status of under-five years children in coastal part of Bangladesh. So far as we know, few study conducted, but they has also ignored multiple interrelated contributing factors of malnutrition. Therefore, the present study was aimed to assess the nutritional status of the children (5-59 months) of under five years in the southern part of Bangladesh and more specifically to find out and investigate the demographic, socioeconomic and health factors associated with anthropometric underdevelopment of children (5-59 months), and to explore the association between various demographic and socioeconomic variables responsible for contributing child nutritional status.

\section{Methods}

\subsection{Subjects}

This study was conducted at BamnaUpazilla of Barguna district. It is a coastal district under the division of Barisal and situated at the Southern region of Bangladesh.
Bamnaupazillawas estimated population of 66,000 people [11].Itis an interventional areaof many Non-Government Organization (NGO).Purposive sampling procedure was used to select the households and subjects. Four villages of Bamnaupzilla were first selected. 100 households from each village were selected randomly. Those households have no children within the range of 6-59 months of age were excluded from the study. Those households havechildren of both sexes and are registered in any intervention program and those mothers/caregiver were willing to participate were included in the study. The subjects were selected from low, middle and high income families. Some exclusion criteria as children with malnutrition resulting from cystic fibrosis, metabolic and endocrine disorders were excluded from the study. Finally, a total of 175 children (6-59 months age)and their mother/ caregiver from each of the 175 households were selected for the study.

\subsection{Survey Procedure}

A structured questionnaire was used for the survey and mothers or caregivers of the children were askedfor face to face interview. In addition, health examination of the children was performed by the survey team. Three survey teams each containing 2-3 members was assigned to visit the households and to conduct the survey. The study was conducted from October 2012 to August 2013. The source of possible error of the survey was also explained in details to minimize the error. Each survey team was also assigned to visit not more than two householdsper day to ensure quality of data to be collected. The quality of the interview and examination was ensured by repeated pretest. At the end of each day, the collected recording was evaluated by the experts to ensure completeness and consistency. Incomplete and inconsistent reporting was corrected by re-visit and re-examine the relevant households. Informed written consent was taken from every respondent explaining the nature and purpose of the study and it was confirmed thatthe personal information will be kept confidential. A prior permission to perform this study was also taken from Mayor of the BamnaUpazilla.

\subsection{Demographic and Socioeconomic Characteristics}

A detail questionnaire containing both closed and openended question were used to collect the demographic and socio-economic characteristics. Age and sex of the children were recorded. Number of family member was categorized into 2-4, 5-6 and 7-8 and collected as on. Education level of the parent was categorized into illiterate, up to class five, SSC, HSC and BA or more to collect the level of education of both parents. Occupation of parents was also categorized and collected. Types of latrine and water used in household activities were recorded to measure the sanitary condition of the family. Hand washing practice of the mother (children age 6-23 months) and children (children age 24-59 months) and the incidence of diarrhea among children during the last month was recorded. Breastfeeding practice was categorized into exclusive breastfeeding (mother's milk only, with the 
exclusion of all other food or drink) and non-exclusive breastfeeding and colostrums feeding practice. The independent variables such as practice of using iodized salt in cooking and family incomes were also studied. The classification of family income in this study was made according toGross National Income (GNI) per capita of 2006 and using the calculation of World Bank (WB)and categorizes as low-income group with monthly family income $\mathrm{BDT} \leq 5000$, lower middle-income, upper middleincome and high-income group with monthly family income BDT 5001 to 10000,10001 to 20000 and $>20000$ respectively.

\subsection{Nutritional Status}

Anthropometric measurement of the studied children (age 6-59 months) was done to evaluate the growth and development of the children, according to the World Health Organization (WHO) guidelines for field assessment [12].The body weight was measured using a platform beam scale. Portable weighing scales (Seca Model 881) were used to measure weight of children. Light clothing was ensured during the measurement and the scale were calibrated every morning and checked for accuracy. When it was difficult to ensure light clothing,the average weight of the cloths was evaluated and deducted from the measurement. Weights were recorded to the nearest $0.1 \mathrm{~kg}$. Children who were unable to stand on the scale were weighed with the mother or caregiver, then the mother/caregiver was weighed alone, and the difference was used to obtain the net weight of the child. The length/height was measured with an appropriate length scale with minimal cloths. A length scale consists of a metric tape affixed to a vertical surface and a movable headpiece attached to the vertical surface that can be brought down to the crown of the head. The position of the eyes and ear lobes were horizontal, feet were together, knees straight and heels, buttocks and shoulders blades were in contact with vertical surface of length scale. Arms were hanging freely at the sides with palm facing the thighs. The headpieces were brought down until it touched the head; sufficient pressure was applied to compress the hair and length/height was measured to the nearest centimeter.Measurements of both weight and height were done in triplicate to minimize the measurement error. Adequacy of dietary intake of children during the previous day of the visit was determined by a 24 hoursdietary recall method and food intake pattern was measured by a specific food frequency questionnaire (FFQ) for the last 30 days.

Wasting (emaciation), stunting (growth retardation) and underweight were defined as weight-for-height, height-forage and weight-for-age and classified according to standard deviation units (z-scores), based on the WHO criteria[13]. Wasting (weight-for-height Z-score-WHZ) indicates emaciation or thinness and defined by a WHZ of $<-2$. It is usually associated with recent nutritional deficiency and depends on availability of foods and/or prevalence of disease. Stuntingrepresented by low height-for-age z-score (HAZ) and it is usually resulted from inadequate food intake for an extended periods, poor dietary quality, increased morbidity and a combination of these and is defined by a HAZ of $<-2$. Weightfor-age z-score (WAZ) is combined form of weightfor-height and height-for-age and indicate the presence of both acute and chronic malnutrition and defined by a WAZ of $<-2$ as underweight. A z-score of $<-3$ defines severe levels of each of the indices. The WHO Anthro software (version 3.2.2) was used to analyze the nutritional status of children[14].

\subsection{Ethical Standards}

An informed written consent was taken from every respondent explaining the nature and purpose of the study and it was confirmed that the personal information will be kept confidential. In addition, this study was conducted according to the guidelines laid down in the Declaration of Helsinki protocols.

\subsection{Statistical Analysis}

SPSS software, version 18.0 (SPSS Inc, Chicago, IL, USA) was used to conducted the data analysis. Relative distributions of the children according to the category of the socio-economic and demographic characteristics were analyzed using descriptive statistics and were expressed both in number and percentage. The prevalence of malnutrition (wasting, stunting and underweight) was expressed according to the degree of severity and both in number and percentage. Association between each of independent variable (socioeconomic and demographic characteristics) and dependent variable (degree of severity of malnutrition) was done using Chi-square test. Crosstab analysis was employed to analyze the Odd-Ratio (OR) and Confident Interval (CI) which indicatesthe odd of having malnutrition (mild, moderate and severe) among exposed over non-exposed children. Statistical significance was set at $\mathrm{P} \leq 0.05$.

\section{Results}

\subsection{Socio-Economic and Demographic Characteristics of the Study Subjects}

The socioeconomic and demographic characteristics were studied for the respondentsand their children of 175 households. The most of the children were selected in the age groups of 6-31 months, which is about $84.6 \%$ and the remaining percentage of children's age were above 31 months of age. The numbers of female children were found to be more than the number of male and the percentage was found to $58.3 \%$ and $41.7 \%$ respectively. It was also shown that only $5.7 \%$ respondents were found to the family member of eight (08) or more whereas more than $46 \%$ children were in small family. However, it was noticeable that 105 children (60\%) had 3-4 siblings and about 148 children (84\%) werethe first or second child of their parents. In addition, $61.7 \%$ father of the studied children was found to complete education up to five classes, however more than $60 \%$ of mother was found to illiterate. Only $2.9 \%$ fathers were completedBachelor degreeor more whereas no mother was 
found to complete Bachelor degree.Father's education level was found to be significantly associated with the number of children.It was also found that $31.4 \%$ of the fathers arelabor. The second most common profession of father was farming, as $25.1 \%$ of them based on agriculture. Father's occupation as businessman, service holder and fisherman was assessed to $16.0 \%, 15.4 \%$ and $2.3 \%$ respectively. Majority of mother was found as housewives $(92.6 \%)$. Only one mother $(0.6 \%)$ was found to be involved in service. The monthly family income of children family was varied from $\leq 5000$ to $\geq 21000$ Taka. The Majority of family (53.1\%) earns below 5000 Taka. The income statuses of $34.3 \%$ families were belongs to the middle class (between Taka. 6000-10000). The number of higher middle class (11000-20000) families were represented only $10.9 \%$ of the study population.

It was also found that only $5.7 \%$ of the children were introduced with the first milk (colostrum) of their mother. Majority of the motherwere found to have no idea ofcolostrum feeding. It isalso reported that more than $60 \%$ of children were underfed at their last day, which obliquely expresses the overall inadequate child feeding practices. Only $25.71 \%$ of children were found to get exhaustive breast feeding. The association of exclusive breastfeeding practice with the sex of children was found to non-significant. A noticeable number $(91.4 \%)$ of family was found to use iodized salt in cooking. It was found that majority of the households $(59.4 \%)$ use semi-paka latrines in contrast to $36.6 \%$ paka latrines. Few households were using open field i.e.those didn't use either paka or semi-paka latrines. 31.4\% of children were found to wash their hands before meals and after defecation. In addition, $51 \%$ of the households were usedtube-well water, $39.4 \%$ pond water and $9 \%$ surface water. It was also shown that $17.1 \%$ of children experienced with diarrheal diseases during the last month whereas most of the children $(82.9 \%)$ were freed from diarrheal diseases.

\subsection{Nutritional Status of the Children}

Nutritional status of the studied children were expressed as weight for height, height for age and weight for age $\mathrm{Z}$ score and referred to as wasting, stunting and underweight. It was found that $40.6 \%$ children were wasted whereas $60 \%$ and $68.6 \%$ were stunted and underweight, respectively, the results are presented in the Table 1 . Highest numbers of children were found to be moderately malnourished whereas only $2.9 \%$ and $4.6 \%$ children were found to be severely wasted and underweight respectively. However, the percentage of severely stunted child was found to be higher $(20.6 \%)$ than the wasted and underweight children. The percentage of normal children was found to $59.4 \%$ who had adequate weight as compared to their height in contrast to $13.7 \%$ mildwasted and $24 \%$ moderate-wasted children respectively who had inadequate weight as compared to their height. Among the 175 studied children, only 45 were found to get breastfeed exclusively and the rest of them were found to breastfed non-exclusively and 44 children of them were found moderately underweight whereas this number is only 15 for exclusively breast fed children. Only 13 children of exclusively breastfeeding were found to be moderately stunted as compared to 31 children of non-exclusive breastfeeding. But, surprisingly 9 children of exclusively breast feeding were found to be normal as compared to 61 children of non-exclusive breast feeding. In addition, only 17 children of exclusively breastfeeding were found to be moderately wasted as compared to 25 children of nonexclusive breast feeding. All the other data of exclusively breastfeeding were presented in the Table 2. The degree of severity of malnutrition according to the age of children was found to $83.4 \%$ of children of up to 2 years of age and $10 \%$ of children of age from 25 to 59 months were found to severely malnourished respectively.

Table 1. Specific Nutritional status of the study subjects according to WHO classification.

\begin{tabular}{|c|c|c|c|c|}
\hline \multirow{3}{*}{ Cutoff Points } & \multicolumn{4}{|c|}{ Anthropometric Indicators } \\
\hline & WHZ (Wasting) & HAZ (Stunting) & \multicolumn{2}{|c|}{ WAZ (Underweight) } \\
\hline & $n(\%)$ & $n(\%)$ & $n(\%)$ & \\
\hline $\operatorname{Normal}( \pm 1 \mathrm{SD})$ & $104(59.4)$ & $70(40.0)$ & $55(31.4)$ & \\
\hline Mild (-2.00to -1.01) & $24(13.7) 7$ & $25(14.3)$ & $53(30.3)$ & \\
\hline Mode $(-2.01$ to -3.00$)$ & $42(24.0)$ & $44(25.1)$ & $59(33.7)$ & $120(68.6)$ \\
\hline Severe $<-3.0$ & $5(2.9)$ & $36(20.6)$ & $8(4.6)$ & \\
\hline Total $n(\%)$ & $175(100)$ & $175(100)$ & $175(100)$ & \\
\hline
\end{tabular}

It was observed that breastfeeding practice was significantly associated with stunting and underweight of children. Hand washing practice was significantly associated with wasting of children. Diarrheal disease was not significantly associated with nutritional status indicators. Colostrums feeding practice was significantly associated with wasting of children. The father's education was found to be significantly associated with both wasting and stunting whereas mother's education level was not found to be significantly associated with children's nutritional status. Majority of mild (68\%) and moderate stunting (75\%) children were assessed who didn't wash their hands before and after meal. It was also shows that children with hand washing practice were less severely stunted (33.3\%) compared to the children without this health practice $(66.7 \%)$. The prevalence of stunted children was found higher among children who were not fed with the first milk of their mothers. The prevalence of wasting was fairly low among children those were not fed with colostrums than those fed. Prevalence of underweight children was found higher among children whose fathers were illiterate than those of literate, however was not found significantly associated. Most of the 
severely underweight children (75\%) were found to have illiterate father. The children with illiterate fathers had higher stunting, about $72.5 \%$ of mild and $66.7 \%$ of severe. It was also found that children of illiterate fathers had higher mild (73.3\%) and moderate wasting (89.9\%) compared to children with literate fathers. Furthermore, this study revealed that families with lower monthly income were found to have higher incidence of malnutrition in the form of wasting, stunting, and underweight. The magnitude of wasting and stunting and underweight were found to be significantly associated with increasing family income and a decreasing trend of malnutrition was found with the increase of monthly family income. Families having monthly income below 5000 taka are shown to have the highest rate of wasting, stunting and underweight, whereas lowest rate was found to the children with family income greater than BDT 21000, data were presented in the Table 3.

Unadjusted association of demographic and socioeconomic risk factors and children malnutrition $(<-2.01 \mathrm{z}$ score) are shown in Table 4 . The category of malnutrition was dichotomize and set $<-2.01 \mathrm{Z}$-score as the presence of malnutrition (moderate and severe) and $>-2$ Z-score as normal (normal and mild).It was found that the odd of having stunting and underweight was slightly higher among children those who don't follow the standard hand washing practice, however was not found significantly associated $(\mathrm{OR}=1.259$; $95 \% \mathrm{CI}=0.661-2.398$ and $\mathrm{OR}=1.127 ; 95 \% \mathrm{CI}=0.582$ 2.181). Presence of diarrheal disease shown the similar trend of having wasting and underweight $(\mathrm{OR}=1.252 ; 95 \% \mathrm{CI}=$ $0.498-3.144$ and $\mathrm{OR}=1.295 ; 95 \% \mathrm{CI}=0.565-2.968)$. Colostrum feeding was found significantly associated with stunting, however, surprisingly, the odd of having wasting, stunting and underweight was found lower among children those does not fed with colostrums than those fed with colostrum (Table 4). Monthly family income follows the same trend. Children whose fathers were illiterate were found to have twice odd of having wasting, stunting and underweight than those children with literate father $(\mathrm{OR}=$ $2.280,95 \% \mathrm{CI}=0.934-5.568$; OR $=2.104,95 \% \mathrm{CI}=0.862$ 5.137 and $\mathrm{OR}=1.830,95 \% \mathrm{CI}=0.725-4.621)$, although found non-significant.

Table 2. Relation between socio-demographic variables and nutritional status of the Children.

\begin{tabular}{|c|c|c|c|c|c|c|}
\hline & \multicolumn{2}{|c|}{ Exclusive Breast Feeding } & \multicolumn{2}{|c|}{ Hand Washing Practice } & \multicolumn{2}{|c|}{ Diarrheal Disease } \\
\hline & Yes & No & Yes & No & Yes & No \\
\hline & $n(\%)$ & $n(\%)$ & $n(\%)$ & $n(\%)$ & $n(\%)$ & $n(\%)$ \\
\hline \multicolumn{7}{|l|}{ WHZ (Wasting) } \\
\hline $\operatorname{Normal}( \pm 1 \mathrm{SD})$ & $23(22.1)$ & $81(77.9)$ & $35(33.7)$ & $69(66.3)$ & $85(81.7)$ & $19(18.3)$ \\
\hline Mild(-1.01 to -2.00$)$ & $5(20.8)$ & $19(79.2)$ & $2(8.3)$ & $22(91.7)$ & $20(83.3)$ & $4(16.7)$ \\
\hline Moderate(-2.01to-3.00) & $17(40.5)$ & $25(59.5)$ & $15(35.7)$ & $27(64.3)$ & $36(85.7)$ & $6(14.3)$ \\
\hline Severe $(<-3.00)$ & $0(0.0)$ & $5(100)$ & $3(60.0)$ & $2(40.0)$ & $4(80.0)$ & $1(20.0)$ \\
\hline Total n (\%) & $45(25.7)$ & $130(74.3)$ & $55(31.4)$ & $120(68.6)$ & $145(82.9)$ & $30(17.1)$ \\
\hline Pearson Chi-Square ( $p$ value) & \multicolumn{2}{|l|}{$7.52(0.057)$} & \multicolumn{2}{|c|}{$8.431(0.038)$} & \multicolumn{2}{|c|}{$0.367(0.947)$} \\
\hline \multicolumn{7}{|l|}{ HAZ (Stunting) } \\
\hline - $\operatorname{Normal}( \pm 1 \mathrm{SD})$ & $9(12.9)$ & $61(87.1)$ & $24(34.3)$ & $46(65.7)$ & $56(80.0)$ & $14(20.0)$ \\
\hline - Mild(-1.01 to -2.00$)$ & $8(32.0)$ & $17(68.0)$ & $8(32)$ & $17(68)$ & $23(92.0)$ & $2(8.0)$ \\
\hline - Moderate(-2.01 to -3.00$)$ & $13(29.5)$ & $31(70.5)$ & $11(25)$ & $33(75)$ & $38(86.4)$ & $6(13.6)$ \\
\hline - Severe $(<-3.00)$ & $15(41.7)$ & $21(58.3)$ & $12(33.3)$ & $24(66.7)$ & $28(77.8)$ & $8(22.2)$ \\
\hline Total n (\%) & $45(25.7)$ & $130(74.3)$ & $55(31.4)$ & $120(68.6)$ & $145(82.9)$ & $30(17.1)$ \\
\hline Pearson Chi-Square ( $p$ value) & \multicolumn{2}{|l|}{$11.70(0.008)$} & \multicolumn{2}{|c|}{$1.173(0.759)$} & \multicolumn{2}{|c|}{$2.908(0.406)$} \\
\hline \multicolumn{7}{|l|}{ WAZ (Underweight) } \\
\hline - Normal( $\pm 1 \mathrm{SD})$ & $1(1.8)$ & $54(98.2)$ & $19(34.5)$ & $36(65.5)$ & $43(78.2)$ & $12(21.8)$ \\
\hline - Mild(-1.01 to -2.00$)$ & $24(45.3)$ & $29(54.7)$ & $16(30.2)$ & $37(69.8)$ & $45(84.9)$ & $8(15.1)$ \\
\hline - Moderate(-2.01 to -3.00$)$ & $15(25.4)$ & $44(74.6)$ & $17(28.8)$ & $42(71.2)$ & $51(86.4)$ & $8(13.6)$ \\
\hline - Severe $(<-3.00)$ & $5(62.5)$ & $3(37.5)$ & $3(37.5)$ & $5(62.5)$ & $6(75.0)$ & $2(25.0)$ \\
\hline Total n (\%) & $45(25.7)$ & $130(74.3)$ & $55(31.4)$ & $120(68.6)$ & $145(82.9)$ & $30(17.1)$ \\
\hline PearsonChi-Square ( $p$ value) & \multicolumn{2}{|l|}{$32.735(0.00)$} & \multicolumn{2}{|c|}{$0.610(0.894)$} & \multicolumn{2}{|c|}{$1.884(0.597)$} \\
\hline
\end{tabular}


Table 2. Continued

\begin{tabular}{|c|c|c|c|c|c|c|}
\hline & \multicolumn{2}{|c|}{ Colostrum Feeding } & \multicolumn{2}{|c|}{ Father's Education } & \multicolumn{2}{|c|}{ Mother's Education } \\
\hline & Yes & No & Illiterate & Literate & Illiterate & Literate \\
\hline & $n(\%)$ & $n(\%)$ & $n(\%)$ & $n(\%)$ & $n(\%)$ & $n(\%)$ \\
\hline \multicolumn{7}{|l|}{ WHZ (Wasting) } \\
\hline $\operatorname{Normal}( \pm 1 \mathrm{SD})$ & $4(3.8)$ & $100(96.2)$ & $30(93.8)$ & $2(6.3)$ & $21(19.8)$ & 11(15.9) \\
\hline Mild(-1.01 to -2.00$)$ & $1(4.2)$ & $23(95.8)$ & $44(73.3)$ & $16(26.7)$ & $40(37.7)$ & $20(29.0)$ \\
\hline Moderate(-2.01to-3.00) & $5(12)$ & $37(88.1)$ & $71(89.9)$ & $8(10.1)$ & $42(39.6)$ & $37(53.6)$ \\
\hline Severe $(<-3.00)$ & $0(0.0)$ & $5(100)$ & $4(100)$ & $0(0)$ & $3(2.8)$ & $1(1.4)$ \\
\hline Total n (\%) & $10(5.7)$ & $165(94.3)$ & $149(85.1)$ & $26(14.9)$ & $106(60.7)$ & $69(39.4)$ \\
\hline Pearson Chi-Square ( $p$ value) & \multicolumn{2}{|l|}{$4.071(0.254)$} & \multicolumn{2}{|c|}{$10.584(0.014)$} & \multicolumn{2}{|c|}{$3.438(0.329)$} \\
\hline \multicolumn{7}{|l|}{ HAZ (Stunting) } \\
\hline - $\operatorname{Normal}( \pm 1 \mathrm{SD})$ & $1(1.4)$ & $69(98.6)$ & $40(90.9)$ & $4(9.1)$ & $28(26.4)$ & $16(23.2)$ \\
\hline - Mild(-1.01 to -2.00$)$ & $0(0.0)$ & $25(100)$ & $37(72.5)$ & $14(27.5)$ & $35(33.0)$ & $16(23.2)$ \\
\hline - Moderate(-2.01 to -3.00$)$ & $6(14)$ & $38(86.4)$ & $68(91.9)$ & $6(8.1)$ & $39(36.8)$ & $35(50.7)$ \\
\hline - Severe $(<-3.00)$ & $3(8.3)$ & $33(91.7)$ & $4(66.7)$ & $2(33.3)$ & $4(3.8)$ & $2(2.9)$ \\
\hline Total n (\%) & $10(5.7)$ & $165(94.3)$ & $149(85.1)$ & $26(14.9)$ & $106(60.6)$ & $69(39.4)$ \\
\hline Pearson Chi-Square ( $p$ value) & \multicolumn{2}{|l|}{$9.485(0.023)$} & \multicolumn{2}{|c|}{$11.834(0.008)$} & \multicolumn{2}{|c|}{$3.570(0.312)$} \\
\hline \multicolumn{7}{|l|}{ WAZ (Underweight) } \\
\hline • Normal( $\pm 1 \mathrm{SD})$ & $1(0.0)$ & $55(100)$ & $48(87)$ & $7(12.5)$ & $32(30.2)$ & $23(33.3)$ \\
\hline - Mild(-1.01 to -2.00$)$ & $4(9.4)$ & $48(90.6)$ & $41(77.4)$ & $12(22.6)$ & $37(34.9)$ & $16(23.2)$ \\
\hline - Moderate(-2.01 to -3.00$)$ & $5(8.5)$ & $54(91.5)$ & $54(91.5)$ & $5(8.5)$ & $31(29.2)$ & $28(40.6)$ \\
\hline - Severe $(<-3.00)$ & $0(0.0)$ & $8(100)$ & $6(75)$ & $2(25)$ & $6(5.7)$ & $2(2.9)$ \\
\hline Total $n(\%)$ & $10(5.7)$ & $165(94.3)$ & $149(85.1)$ & $26(14.9)$ & $106(60.6)$ & $69(39.4)$ \\
\hline PearsonChi-Square ( $p$ value) & \multicolumn{2}{|l|}{$3.301(0.348)$} & \multicolumn{2}{|c|}{$5.286(0.152)$} & \multicolumn{2}{|c|}{$4.316(0.299)$} \\
\hline
\end{tabular}

†The variables are significant when $\mathrm{P}<0.05$

Table 3. Relation between Monthly Family Income and nutritional status of the Children.

\begin{tabular}{|c|c|c|c|c|}
\hline & \multicolumn{4}{|c|}{ Monthly income of the respondent family } \\
\hline & $\leq \mathbf{5 0 0 0}$ Taka & 6000-10000 Taka & 11000-20000 Taka & $\geq 21000$ Taka \\
\hline & $n(\%)$ & $n(\%)$ & $n(\%)$ & $n(\%)$ \\
\hline \multicolumn{5}{|l|}{ WHZ (Wasting) } \\
\hline Normal ( $\pm 1 \mathrm{SD})$ & $23(71.9)$ & $8(25.0)$ & $1(3.1)$ & $0(0)$ \\
\hline Mild (-1.01 to -2.00$)$ & $34(56.7)$ & $14(23.3)$ & $12(20.0)$ & $0(0)$ \\
\hline Moderate $(-2.01$ to -3.00$)$ & $32(40.5)$ & $38(48.1)$ & $6(7.6)$ & $3(3.8)$ \\
\hline Severe $(<-3.00)$ & $4(100)$ & $0(0)$ & $0(0)$ & $0(0)$ \\
\hline Total n (\%) & $93(53.14)$ & $60(34.29)$ & $19(10.86)$ & $3(1.71)$ \\
\hline $\begin{array}{l}\text { Pearson Chi-Square } \\
\text { ( } p \text { value })\end{array}$ & $\begin{array}{l}26.189 \\
(0.002)\end{array}$ & & & \\
\hline \multicolumn{5}{|l|}{ HAZ (Stunting) } \\
\hline Normal ( $\pm 1 \mathrm{SD})$ & $30(68.2)$ & $10(22.7)$ & $4(9.1)$ & $0(0)$ \\
\hline Mild (-1.01 to -2.00$)$ & $29(56.9)$ & $13(25.5)$ & $9(17.6)$ & $0(0)$ \\
\hline Moderate $(-2.01$ to -3.00$)$ & $31(41.9)$ & $35(47.3)$ & $6(8.1)$ & $2(2.7)$ \\
\hline Severe $(<-3.00)$ & $3(50.0)$ & $2(33.3)$ & $0(0)$ & $1(16.7)$ \\
\hline Total n (\%) & $93(53.14)$ & $60(34.29)$ & $19(10.86)$ & $3(1.71)$ \\
\hline $\begin{array}{l}\text { Pearson Chi-Square } \\
(p \text { value })\end{array}$ & $\begin{array}{l}23.634 \\
(0.005)\end{array}$ & & & \\
\hline \multicolumn{5}{|l|}{ WAZ (Underweight) } \\
\hline Normal ( $\pm 1 \mathrm{SD})$ & $36(65.5)$ & $13(23.6)$ & $6(10.9)$ & $0(0)$ \\
\hline Mild (-1.01 to -2.00$)$ & $28(52.8)$ & $17(32.1)$ & $8(15.1)$ & $0(0)$ \\
\hline Moderate $(-2.01$ to -3.00$)$ & $25(42.4)$ & $27(45.8)$ & $5(8.5)$ & $2(3.4)$ \\
\hline Severe $(<-3.00)$ & $4(50.0)$ & $3(37.5)$ & $0(0.0)$ & $1(12.5)$ \\
\hline Total n (\%) & $93(53.14)$ & $60(34.29)$ & $19(10.86)$ & $3(1.71)$ \\
\hline $\begin{array}{l}\text { Pearson Chi-Square } \\
(p \text { value })\end{array}$ & $\begin{array}{l}17.358 \\
(0.043)\end{array}$ & & & \\
\hline
\end{tabular}


Table 4. Unadjusted association of demographic and socio-economic risk factors and risk of being malnourished (<-2.01 Z Score) among studied children. ${ }^{\dagger}$

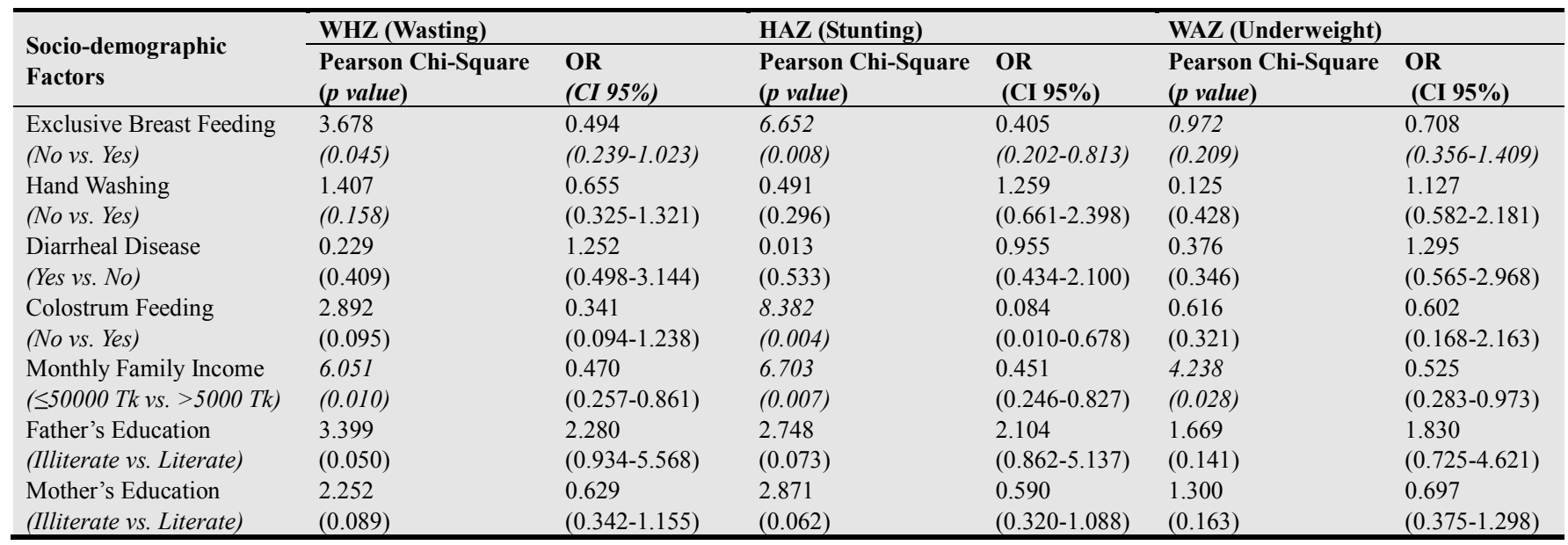

${ }^{\dagger}$ Mmalnutrition was dichotomize and set $<-2.01 \mathrm{Z}$ Score as the presence of malnutrition and $>-2 \mathrm{Z}$ Score as normal.

\section{Discussion}

Infant and children nutrition is an important part for his/her development throughout the life as the earliest stages of fetal development, at birth, through infancy, childhood, adolescence, and on into adulthood, proper food and good nutrition are essential for survival, physical and mental development, performance and productivity, health and wellbeing. Malnutrition in under-five year children has a pervasive impact on the physical well-being and socioeconomic condition and causes serious public health problem in Bangladesh. Some literature reported that socioeconomic and socio-demographic conditions, together with feeding practices, are important determinants of malnutrition in developing countries [15,16].Demographic characteristics such as the child's age and sex, birth intervals (both preceding and following), and mother's age at childbirth are effectively associated with child nutrition [17].This study reported that the prevalence of stunting, wasting and underweight were found to be $60,40.6$ and $68.6 \%$ however, BDHS 2011 were reported to $41.3,15.6$ and $36.4 \%$ respectively. This discrepancy can be explained as the higher rate of malnutrition and extensive growth retardation among under-five year children living in coastal area of Bangladesh.

In rural community in Bangladesh, colostrumsfeeding arethought to be harmful for the infant and usually for the first 1 to 2 days after delivery. Our study reveals that more than $90 \%$ children were deprived to get the priceless first breast milk and high prevalence of pre-lacteal liquid and consequently recommended to practices of giving honey or honey with water, sugar water or even oil instead of colostrums. Although this action delays the onset of breastfeeding and causes breast refusal and reduces the suckling ability of the child [18].Our study showed thatthe prevalence of stunting was higher in the children who were not fed with the first milk of mother andthe relation between stunting and colostrums feeding was found to significant $(\mathrm{P}<.05)$. A significant association among child malnutrition and exclusive breast feeding practice was found in this current study; however the percentage of children those who got breastfeeding exclusively were only $25 \%$. It also mentioned that nutritional status was worst in children who were not breastfed exclusively and about $70.5 \%$ of moderate and $58.3 \%$ of severe stunting was found among non EBF children.

It is noticeable that a significant association was found between father's education and child nutrition, and the degree of having stunting, wasting and underweight was found almost 2 times more in children with illiterate father. However, many studies suggested that maternal education is a crucial factor for nutritional status of children in developing countries $[19,20]$.Surprisingly this study did not show any potential effect of maternal literacy on child malnutrition. This finding can be supported by the early literature that showed in Bangladesh, increasing paternal education is associated with greater decreases in the odds of malnutrition than to maternal education [21].Several studies have also shown that parental education is associated with more efficient management within limited household resources, greater utilization of available health care services, better health promoting behaviors, lower fertility and more childcentered caring practices, these all factors associated with better child health and nutrition [22].Another study, on 18,544 children from Metro Cebu, Philippines, also showed that father's education was a more consistent determinant of child stunting than maternal education [23]. The level of paternal education is usually related to household income, since more educated fathers usually earn more money and marry women of a comparable level of education. Besides,illiterate father are shown to have more than 3 children and adequacy of food for each family member is sometime depends on the number of family member and this might be connected in developing malnutrition in children with illiterate father.

A trend of decreasing children stunting with increasing family income was shown in a comparative study in more than 15 countries [24].In this study, the magnitude of wasting, stunting and underweight were found to be inversely related 
with the increasing of family income. Chi-square test indicates a significant association among wasting, stunting and underweight and monthly family income $(\mathrm{p} \leq 0.05)$. Howevercrosstab analysis gives abnormal odd ratio (OR $<1.00$ ) and this might be due to small sample size. Majority of severely underweight children $(50 \%)$ was found to live in lower economic class families, whereas very few severely underweight children (12.5\%) were found in upper middle class families.Furthermore, unfavorable health environment caused by inadequate water and sanitation can increase the probability of infectious diseases and indirectly cause certain types of malnutrition [25].Diarrhea and other infectious diseases manifested in the form of fever affect both dietary intake and utilization, which may have a negative effect on improved child nutritional status. Hand-washing, an important hygienic practice acts as an effective indicator for nutritional wellbeing of the children as well and proper hand washing practice among infants and children can prevent the intensity of infectious disease at a greater extent. Though diarrhea and hand washing practice are important indicators, neither were found to be significantly $(p>0.05)$ associated with children nutritional status, except only wasting, which was significantly associated with hand washing practice. $64.3 \%$ children suffer from moderate acute malnutrition that did not wash hand. Our study also reveals that about $86.4 \%$ moderate and $75.0 \%$ severe underweight children those who experienced diarrhea in their last month.

\section{Conclusions}

This study reveals that the pervasiveness of under-nutrition among under-five year children is more pronounced in southern part (Barguna) of Bangladesh due to contributing overall inadequate demographic and socio-economic status that influences poor nutrition status of children. Illiterate father links to low-economic class and lower middle class families that causes acute and chronic malnutrition in their children. Children without hand-washing practices were more wasted. Inappropriate and inadequate child feeding practices such as lack of proper pre-lacteal feeding and early cessation of breastfeeding predominates in the area and also contributes to the poor nutritional status of children. In addition, the degree of malnutrition was found to more prevalent in the early stage of children. This study also indicates poor nutritional and health status of children and household food insecurity in the coastal region. Therefore, it is recommended the necessity of the regular arrangement of community nutrition and public health intervention programme to increase proper health practices such as early initiation of colostrum feeding, exclusive breast feeding up to six months of child age and hand-washing practices in the people of costal area. However, due to financial constraint, the present study was carried out with relatively small sample size which might have undermined the ability of the study to demonstrate the actual contributing factors associated with poor nutritional status. A better result can be obtained on exercising large sample size covering wider research area in coastal region.

\section{Acknowledgements}

The authors wish to thank the study participants for their contribution to the research. The authors would specifically like to thank the Mayor of the BamnaUpazilla of Barguna district in Bangladesh for their research assistance and support. In addition, we wish to confirm that there are no known conflicts of interest associated with this publication and there has been no significant financial support for this work that could have influenced its outcome.

\section{References}

[1] United Nations Children's Fund,"The State of the World's Children 2007. Women and Children: The Double Dividend of Gender Equality," 2007.

[2] C.K Lutter, M.E.G Daelmans, M. De Onis, Kothari, M. Rael, M.T Arimond, M. Deitchler, K. Dewey, M. Blossner, E. Borghi, "Undernutrition, poor feeding practices, and low coverage of key nutrition interventions," Journal of Pediatrics, 2011,vol. 128(6), pp. e1418-27.

[3] A. Jansen,K.O. Bailey,"The Early Detection of Childhood Malnutrition in South Pacific"Geneva, Switzerland, 1972, pp.1-2.

[4] United Nations Children's Fund, "The state of the world's children 2009. Special edition: celebrating 20 years of the convention on the rights of the child,"New York, 2009, pp. 92.

[5] R.E. Black, L.H. Allen, Z.A. Bhutta, L.E. Caulfield, M. de Onis, M. Ezzati, C. Mathers, J. Rivera,"Maternal and Child Undernutrition Study Group. Global and regional exposures and health consequences,"The Lancet,2008,vol. 371, pp. 24360 .

[6] C.G. Victora, M. de Onis, P.C. Hallal, M. Blössner, R. Shrimpton,"Worldwide timing of growth faltering: revisiting implications for interventions."Journal of Pediatrics, 2010, vol. 125(3), pp. e473-80.

[7] The World Bank. Bangladesh Development Series,"The Bangladesh Integrated Nutrition Project Effectiveness and Lessons," 2005.

[8] Bangladesh Demographic and Health Survey,"National Institute of Population Research and Training,"Dhaka, Bangladesh, 2011.

[9] WFP/UNICEF/IPHN,“Household Food Security and Nutrition Assessment," 2009, http://www.unicef.org/bangladesh/HFSNA-FINAL--20100608.pdf

[10] A. Rahman, S. Chaudhury, A. Karim, S. Ahmed, "Factors Associated with Nutritional Status of Children in Bangladesh: A Multivariate Analysis" Demography India., 2008, Vol. 37, pp. 95-109.

[11] H. Wamani, A.N. Astrom, S. Peterson, J.K. Tumwine, T. Tylleskär,"Predictors of poor anthropometric status among children under 2 years of age in rural Uganda,"Public Health Nutrition, 2006,vol. 9(3), pp. 320-6.

[12] World Health Organization, "Field Guide on Rapid Nutritional Assessment in Emergencies" Geneva, 1995. 
[13] National Health and Nutrition Examination Survey,“Anthropometry Procedures Manual,"Center for Disease Control, 2009,http://www.cdc.gov/nchs/data/nhanes/nhanes_07_08/ma nual_an.pdf.

[14] World Health Organization,"WHO Child Growth Standards. Length/Height-for-age, Weight-for-age, Weight-for-length, Weight-for-height and Body Mass Index-for-age: Methods and Development,"Geneva, 2006, pp. 306-307.

[15] World Health Organization,"Anthro for personal computers, Version 3.2.2. Software for assessing growth and development of the world's children," Geneva, Available at: http://www.who.int/childgrowth/software/en (accessed 17.01.2014), 2007.

[16] V. Vella, A. Tomkins, A. Borghesi, G.B. Migliori, B.C. Adriko, E. Crevatin, "Determinants of child nutrition and mortality in north-west Uganda." Bulletin WHO, 1992, vol. 70, pp. 637643.

[17] R.K. Mwadime,S.L. Baldwin,"Relationship between household access to food and malnutrition in eastern and Southern Africa,'EastAfr Med J., 1994, vol. 71, pp. 571-79.

[18] A.E. Sommerfelt,M.K. Stewart,"Children's nutritional status. DHS Comparative Studies," No. 12. Calverton, Maryland: Macro International, Demographic and Health Surveys (DHS), 1994.
[19] R. Hong,V. Mishra,"Effect of wealth inequality on chronic under-nutrition in Cambodian children," $J$ Health populNutr.,2006, vol. 24, pp. 89-99.

[20] J.A. Ricci,S. Becker,"Risk factors for wasting and stunting among children in Metro Cebu, Philippines," $A m \quad J$ ClinNutr.,1996, vol. 63, pp. 966-975.

[21] Z. Hassan,"Microcredit programmes. Who participates and to what extent?" BRAC-ICDDR,B Joint Research Project,Dhaka, Bangladesh, 1996, vol. 12.

[22] J.B. McGuire,B.M. Popkin,"Increasing women's resources for nutrition in developing countries," 15th session of the ACC/SCN, New York, 1989.

[23] R.D. Semba, S. de Pee, K. Sun, M. Sari, N. Akhter, M.W. Bloem,"Effect of parental formal education on risk of child stunting in Indonesia and Bangladesh: a cross-sectional study"TheLancet, 2008,vol. 371, pp. 322-28.

[24] Sommerfelt, A. Elizabeth, S. Kathryn,"Children's nutritional status. DHS Comparative Studies" No. 12. Calverton, Maryland, USA: Macro International Inc., 1994.

[25] P.L. Engle, "Care and child nutrition," Theme paper for the international conference on nutrition (ICN): Paper prepared for nutrition section, UNICEF, New York,1992. 